\title{
The effect of suggested program for circuit weight training on the level of some physical, physiological and skills variables for Table Tennis players Dr/ Hossam Hamed Abdelmaged Abdelkhlaek
}

\section{Abstract:}

The aim of this research is to Designing training program thru circuit weight training and observe the effect of this suggested program on the level of some physical, physiological and skills variables for Table Tennis players, the researcher used the experimental method for the experimental one group.

The research sample was been selected from players of Alseeb sporting club in Oman. The sample of the research was (10) players, the researcher applied physiological, physical and skills abilities tests after that he applied the training program thru circuit weight training over a period of (12) weeks, then he performed measurements on physical, physiological and skills abilities test .

The results revealed that there were statistical differences between the Pre-measurement, Tracer- measurement and the post-measurement regards physiological variables, physical abilities and skills variables the researcher recommended to use the circuit weight training over preparation period.

Key words:

circuit weight training, Physical abilities, physiological variables, skills, table tennis.

\section{Introduction:}

Table Tennis is among the sports which were clearly positively affected by the progress in different sports sciences and by the advances in methods of preparation of the players. All of these has helped to raise the standard of the players physically and in skills and planning and helped them to reach the highest level for competition. $(3: 20)$

Nowadays Table Tennis
games are much more
competitive and tough and so
the training in the field, solely,
is not enough, and this showed
very clear in many
international table tennis
competitions. (4: 20)
Thus, it became essential
not to be satisfied with having
skill training, only, of different
skills of Table Tennis. The


complex nature of table tennis with its physical, skills, planning, and intellectual demands would necessitate variable and comprehensive skills and capabilities in order to reach a high level of performance in the field.(6: 20)

As we know progress of science has become the distinctive feature of the era, for its contribution in finding many scientific solutions for many problems in all fields of life in general, and the field of physical fitness in particular. Consequently, the means of training developed, and adopted the principle of integration between the difference science and knowledge that aim at bringing the player to the level that enables him to achieve the highest sports achievements in the field of his specializations within his technical capacities. (11:88)

The training process aims at bringing the individual to the highest sports performances. To achieve the required sports performance, we shall know the starting point and end to set the training programs suitable for the condition of the sports person and to know to what extent has the sports level of the individual reached (12:25).

With the scientific progress, that circuit weight training was found to be one of the best methods of training in terms of affecting in increased or to develop an element of physical fitness in accordance with the type and conditions of performance and the specialized activity (8:35).

Some notes attracted the attention of the researcher through its readings and navigation in the National Information Network and attending many table tennis training sessions and meeting many table tennis coaches. These notes became the backbone for this study. In brief, they are:

1.The trainers do not focus enough on weight training.

2.There is a great lack of physical training programs especially weight training programs and There are whole sports teams who never practiced a weight training program during their whole sports life. (7: 35)

3.There is no codification of training loads in weight training; It is jurisprudential especially when it comes to training of basketball players. This, indirectly, affects the 
training process and the programs which in turn lead to poor technical level of the players and failure to achieve the desired results.

4. Weight training is one of the essential components to succeed in preparing table tennis players. Every player should keep a condensed daily schedule for weight training in addition to the skills training.

According to what was mentioned, and in the light of the importance of controlling and well preparing the training programs and to direct them well because they have a direct influence on the level of skill performance in table tennis, and because the researcher believes that the domain of preparing table tennis players still needs many more comprehensive studies, he tried to find out "The effects of a suggested program for circuit weight training on some physiological and physical variables in table tennis players".

\section{Aims of the research:}

To design a proposed program for circuit weight training for table tennis players, in an attempt to find out:

1.The effect of the proposed program on the level of some physical variables under study.
2.The effect of the proposed program on the level of some physiological variables under study.

3. The effect of the proposed program on the level of some skills variables under study.

\section{Terminology of study:}

circuit weight training is a method or system that has its theoretical and scientific origins, conditions, and fields as well . (9: 24)

\section{Methodology:}

The researcher used the empirical approach because it is suitable for the nature of this study where it relied on the experimental design of the measurements (Pre-, tracer, and Post-) of one experimental group.

\section{Sample:}

The research sample was been selected from players of Alseeb sporting club in Oman. The sample of the research was $(10)$ players, $(1 \cdot)$ players were selected to conduct exploratory studies, and (10) players for basic study, the researcher applied physiological, physical and skills abilities tests after that he applied the training program thru circuit weight training over a period of (12) weeks, then he performed measurements on physiological, physical and skills abilities test. 


\section{Table (1)}

Statistical characterization of the sample in the variables (Length, weight, Age and Training age $)(\mathrm{N}=15)(5$ exploratory studies \& 10 basic study)

\begin{tabular}{l|c|c|c|c|c}
\hline \hline Variables & $\begin{array}{c}\text { Measuring } \\
\text { Unit }\end{array}$ & Mean & Median & $\begin{array}{c}\text { St. } \\
\text { Deviation }\end{array}$ & Skewness \\
\hline \hline Age & Year & 24.6 & 24 & 2.098 & 0.615 \\
\hline Length & CM & 175.1 & 175 & 4.207 & -0.307 \\
\hline Weight & KG & 75.1 & 75 & 4.301 & 0.725 \\
\hline Training Age & year & 9.5 & 9 & 1.457 & 0.316 \\
\hline \hline
\end{tabular}

Table (1) Shows the modality of the distribution of the sample in the variables (Length, weight, Age and

Table (2)

Statistical characterization of the sample in the variables (Muscular power, Performance Endurance, pulse, Vital capacity, Counter Drive and the Loop) $(\mathrm{N}=15)(5$ exploratory studies \& 10 basic study)

\begin{tabular}{|c|c|c|c|c|c|}
\hline Variables & Unit & Mean & Median & $\begin{array}{l}\text { St. Deviation } \\
\end{array}$ & Skewness \\
\hline Muscular power & Meter & 19.5 & 19 & 1.060 & 0.100 \\
\hline $\begin{array}{l}\text { Performance } \\
\text { Endurance }\end{array}$ & Second & 50.4 & 50 & 1.352 & 0.454 \\
\hline $\begin{array}{c}\text { Heart rate } \\
\text { During Rest }\end{array}$ & Pulse/M & 79.2 & 80 & 2.411 & -0.951 \\
\hline Vital capacity & Liter & Y.A & $\mu$ & .170 & $.97 r$ \\
\hline $\begin{array}{c}\text { Forehand } \\
\text { counter drive }\end{array}$ & Rept. & V.7 & $\Lambda$ & $1 . \varepsilon \cdot \varepsilon$ & $\because V V Y_{-}$ \\
\hline $\begin{array}{c}\text { Backhand } \\
\text { counter drive }\end{array}$ & Rept. & 7.9 & V & $1.04 \varepsilon$ & $.1 \leq 7$ \\
\hline Forehand Loop & Rept. & $\varepsilon .9$ & 0 & .094 & $\because \cdots \varepsilon_{-}$ \\
\hline Backhand Loop & Rept. & $\varepsilon .0$ & $\varepsilon$ & 1.110 &.$\leqslant Y O_{-}$ \\
\hline
\end{tabular}

Table ( $r$ ) Shows the modality of the distribution of the sample in the variables (Muscular power, Performance Endurance, pulse, Vital capacity, Counter Drive and
Training Age) where the torsion coefficients are limited to $( \pm 3)$. 
stages and the degrees of training loads, the schedule was set for 12 weeks, at the rate of 3 units of circular weight training every week. Thus, the proposed program included 36 units. The duration of each ranged from $90-120$ minutes. Then, the researcher applied the proposed circular weight training on the sample during the sport season 2017 / 2018 starting from Sunday 8 / 10 / 2017 to Thursday 28 / 12 / 2017. The program was applied under the supervision of the researcher and his assistants.

Legalize the intensity of the training load

Using (Karvonen)

method of heart rate in training as follows:

The maximum heart rate HR $\max =220-$ age $=$ beat $/ \mathrm{min}$. (2:39)

And the researcher using polar watch to rate the loads.

\section{Methods of data collection:}

Reference survey:

The

researcher

conducted a survey of studies and scientific references in table tennis, sports training science and the science of sports physiology that was available to the researcher in order to identify the global and professional variables in operation of the research, as well as identify options in measuring these variables, as well as visited a survey of scientific references specialized in the sport of table tennis, defines basic skills in the sport of table tennis.

The tools used in the research:

Polar watch to regulate the training load in terms of the pulse - the thermometer to measure the length "in centimeters" - the device for the thrower of the table tennis balls- a medical scale to measure the weight "in kilograms"- table tennis- table tennis balls- cones- medical balls 1.5 kilograms weightchalk- stopwatch- meter distance tape measure - long ropes- hammer- tires of different weights- medical balls of different weights- kettlebellRubber band- different weights- training mattresses.

Physical, physiological and skills tests used in the study:

-Throwing a medical ball weighing $1.5 \mathrm{~kg}$... to measure muscular power (modified by the researcher) .

-Table test ... to measure performance endurance. (Edited by the researcher) -Polar watch ... to measure the Heart rate pulse. 
-Dry spirometer test ... to measure vital capacity.

- Forehand counter drive test ... to measure Forehand counter drive.

- Backhand counter drive test ... to measure Backhand counter drive.

- Forehand Loop test ... to measure Forehand Loop drive.

- Backhand Loop test ... to measure Backhand Loop drive.

Scientific Transactions for Tests:

\section{Validated Tests:}

The validity of the tests was calculated by calculating the validity of differentiation by applying them to two

Table (3)

The significance of the differences between the two distinct and non-distinguishing groups in physical, physiological and skill tests ( N1=N2=5)

\begin{tabular}{|c|c|c|c|c|c|c|c|}
\hline \multirow[t]{2}{*}{ Variables } & \multirow[t]{2}{*}{ unit } & \multicolumn{2}{|c|}{ Distinct G. } & \multicolumn{2}{|c|}{$\begin{array}{c}\text { non- } \\
\text { distinguishing }\end{array}$} & \multirow[t]{2}{*}{$\begin{array}{c}\text { Average } \\
\text { Difference }\end{array}$} & \multirow[t]{2}{*}{ T.Test } \\
\hline & & Mean & S.DEV & Mean & S.DEV & & \\
\hline $\begin{array}{l}\text { Muscular } \\
\text { power }\end{array}$ & Meter & $r$. & I.YYO & 10 & $\cdot . \leqslant \leqslant V$ & $0 . Y$ & $* V . \wedge \mu q$ \\
\hline $\begin{array}{l}\text { Performance } \\
\text { Endurance }\end{array}$ & Second & 01.1 & I.r. E & $\varepsilon \varepsilon . Y$ & $1 . r \cdot \Lambda$ & V & $* 9 . \wedge 99$ \\
\hline $\begin{array}{l}\text { Heart rate } \\
\text { During Rest }\end{array}$ & $\mathrm{P} / \mathrm{M}$ & $\vee \wedge . \varepsilon$ & $r . V \varepsilon$ & 10.7 & $1.01 \mathrm{~V}$ & $V . Y$ & $* 4 . Y Y \cdot$ \\
\hline Vital capacity & Liter & ะ.) & $\because \wedge 9 \leq$ & T. $\varepsilon$ & $.0 \leqslant 1$ & $1 . V$ & $* Y . \leqslant V$. \\
\hline $\begin{array}{l}\text { Forehand } \\
\text { counter drive }\end{array}$ & Rept. & A. $\varepsilon$ & $\because 0 \leqslant 1$ & 0.7 & $.0 \leqslant 1$ & Y.A & $*) \leqslant \ldots$ \\
\hline $\begin{array}{l}\text { Backhand } \\
\text { counter drive }\end{array}$ & Rept. & $7 . r$ & $\cdot \varepsilon \leqslant V$ & $r . r$ & $\because A r V$ & $r$. & $* \eta . \vee \cdot \wedge$ \\
\hline $\begin{array}{l}\text { Forehand } \\
\text { Loop }\end{array}$ & Rept. & $7 . Y$ & $\because \wedge \mu V$ & r. & $\because v \cdot V$ & $\varepsilon . r$ & $* Y 1 .$. \\
\hline $\begin{array}{l}\text { Backhand } \\
\text { Loop }\end{array}$ & Rept. & $\varepsilon . Y$ & 1.90 & 1.1 & $\cdot . \wedge r V$ & T. & $* r .0 Y q$ \\
\hline
\end{tabular}

"T" tabulated value at $(0.05)=2.306$ 
Table ( $r)$ showing there is statistically significant differences between the (Distinct group/ nondistinguishing group) groups in the variables under study, which shows deference between the two groups in these variables since the calculated " $T$ " value is more than the tabulated "T" value.

So that the tests can be used.

Table (4)

Correlation coefficient between the results of the first and second apply of the tests under research $\mathrm{N}=$ (5)

\begin{tabular}{|c|c|c|c|c|c|c|}
\hline \multirow{2}{*}{ Variables } & \multirow{2}{*}{ unit } & \multicolumn{2}{|c|}{ First Apply } & \multicolumn{2}{|c|}{ Second Apply } & \multirow{2}{*}{$\begin{array}{c}\mathbf{R} \\
\text { Value }\end{array}$} \\
\hline & & Mean & S.DEV & Mean & S.DEV & \\
\hline Muscular power & Meter & $r$. & 1. rYo & $r \cdot . \Sigma$ & $\cdot \wedge 9 \leqslant$ & $* .91 \%$ \\
\hline $\begin{array}{l}\text { Performance } \\
\text { Endurance }\end{array}$ & Second & $01 . Y$ & $1 . r \cdot \varepsilon$ & $0 . .1$ & 1.90 & $* .91$. \\
\hline Heart rate During Rest & $\mathrm{P} / \mathrm{M}$ & $V \wedge . \varepsilon$ & $r_{.} \cdot V \varepsilon$ & $\Lambda \cdot . \cdot$ & $\because v \cdot v$ & $* . \wedge 0 \mathrm{r}$ \\
\hline Vital capacity & Liter & ร. & $\cdot \wedge 9 \varepsilon$ & $\varepsilon . r$ & 1.90 & 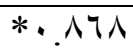 \\
\hline Forehand counter drive & Rept. & $\Lambda . \varepsilon$ & $.0 \leqslant \Lambda$ & $\wedge . \wedge$. & $\cdot \Lambda \mu V$ & $* . \vee \vee 1 \leqslant$ \\
\hline Backhand counter drive & Rept. & $7 . Y$ & $\cdot . \leqslant \leqslant V$ & 0.7. & $\cdot \wedge 9 \leqslant$ & $* . \wedge \vee 0$ \\
\hline Forehand Loop & Rept. & 7.1 & $\cdot \Delta \mu V$ & $7 . \varepsilon$. & $\because \wedge 9 \varepsilon$ & $* . .179$ \\
\hline Backhand Loop & Rept. & $\varepsilon . Y$ & 1.90 & $\varepsilon . Y$ & $1 . \mu \cdot \varepsilon$ & $* . \wedge \varepsilon$. \\
\hline
\end{tabular}

It is evident from Table

(4) that the value of correlation coefficients between the first and second apply of physical, physiological and skills tests ranged between $(0.764 \quad-$ 0.913 ), and these values are statistically significant at a significance level (0.05), which indicates that they have high stability coefficients and the stability of the tests.

\section{Stability for Tests:}

To find the stability of tests, the researcher applied the test and repeat it with time interval of six days, and the researcher used Pearson's simple correlation coefficient to find the correlation coefficient between the results of the first and second apply. 
Table (5)

One-way Anova of the pre-, tracer, and post for sample measurements in the physical, physiological and skill variables under study $\mathrm{N}=\mathbf{1 0}$

\begin{tabular}{|c|c|c|c|c|c|}
\hline Variables & $\begin{array}{l}\begin{array}{l}\text { Source of } \\
\text { the } \\
\text { contrast }\end{array} \\
\end{array}$ & $\begin{array}{c}\text { Freedom } \\
\text { Degree }\end{array}$ & $\begin{array}{l}\text { Sum of } \\
\text { squares }\end{array}$ & $\begin{array}{c}\text { Mean } \\
\text { squares }\end{array}$ & $\begin{array}{l}\text { Anova } \\
\text { Value }\end{array}$ \\
\hline \multirow{3}{*}{$\begin{array}{l}\text { Muscular } \\
\text { power }\end{array}$} & Between Groups & 2 & $Y \cdot V . Y$ & 1.4 .7 & \multirow{3}{*}{$* q \vee .1$ ro } \\
\hline & Within Groups & 27 & $r \wedge . \wedge$ & $1.9 V$ & \\
\hline & Total & 29 & Trч." & & \\
\hline \multirow{3}{*}{$\begin{array}{l}\text { Performance } \\
\text { Endurance }\end{array}$} & Between Groups & 2 & $117 . \wedge 78$ & $0 \Lambda . \varepsilon r \mu$ & \multirow{3}{*}{$* 00.17 \varepsilon$} \\
\hline & Within Groups & 27 & r^.... & 1.09 & \\
\hline & Total & 29 & $1 \leqslant 0 . \leqslant 7 V$ & & \\
\hline \multirow{3}{*}{$\begin{array}{l}\text { Heart rate } \\
\text { During Rest }\end{array}$} & Between Groups & 2 & $111.77 \mathrm{~V}$ & $70 . \wedge \mu r$ & \multirow{3}{*}{$* Y 0.7 \leq q$} \\
\hline & Within Groups & 27 & $79 . r \ldots$ & Y.0TV & \\
\hline & Total & 29 & $r \ldots .97 V$ & & \\
\hline \multirow{3}{*}{$\begin{array}{l}\text { Vital } \\
\text { capacity }\end{array}$} & Between Groups & 2 & $17 . r 7 \mathrm{~V}$ & $\Lambda .1 \mu \mu$ & \multirow{3}{*}{$* \mid \vee . \vee 1}$. \\
\hline & Within Groups & 27 & IY.\&.. &. .509 & \\
\hline & Total & 29 & YA.TTV & & \\
\hline \multirow{3}{*}{$\begin{array}{l}\text { Forehand } \\
\text { counter } \\
\text { drive }\end{array}$} & Between Groups & 2 & Vr.ATV & rT.9rT & \multirow{3}{*}{ * } \\
\hline & Within Groups & 27 & $17 . \cdots$ & .094 & \\
\hline & Total & 29 & 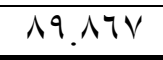 & & \\
\hline \multirow{3}{*}{$\begin{array}{l}\text { Backhand } \\
\text { counter } \\
\text { drive }\end{array}$} & Between Groups & 2 & $00 . Y T V$ & rV.TrT & \multirow{3}{*}{ *ov.Ar } \\
\hline & Within Groups & 27 & $14.9 \ldots$ & $\cdot . \leqslant \vee \wedge$ & \\
\hline & Total & 29 & $7 \wedge .17 V$ & & \\
\hline \multirow{3}{*}{$\begin{array}{l}\text { Forehand } \\
\text { Loop }\end{array}$} & Between Groups & 2 & YI乏.TV & I.V.RT & \multirow{3}{*}{ * ११.११४ } \\
\hline & Within Groups & 27 & r^.q.. & $1 . v \cdot$ & \\
\hline & Total & 29 & $r \leqslant Y .97 V$ & & \\
\hline \multirow{3}{*}{$\begin{array}{l}\text { Backhand } \\
\text { Loop }\end{array}$} & Between Groups & 2 & YTY.ETV & ITI.YT & \multirow{3}{*}{$* \wedge 1 . \wedge r$} \\
\hline & Within Groups & 27 & $\varepsilon r . V \ldots$ & 1.179 & \\
\hline & Total & 29 & T.7.17V & & \\
\hline
\end{tabular}

"F" tabulated value at $(0.05)=3.350$

Table (5) shows that there are statistically significant differences at a level of significance $(0.05)$ between the measurements of the pre, tracer, and post research sample in all the physical and physiological variables under study, and to clarify the significance of the differences 
between these measurements ... The researcher will calculate the lowest significant Table ( 7 )

The significance of the differences between the averages of the measurements of the pre, Tracker and post for research sample in the physical, physiological and skills variables of the sample under study

\begin{tabular}{|c|c|c|c|c|c|c|}
\hline \multirow{2}{*}{ Variables } & \multirow{2}{*}{ Measures } & \multirow{2}{*}{ Mean } & \multicolumn{3}{|c|}{ Deference between Means } & \multirow{2}{*}{$\begin{array}{c}\text { LSD } \\
\text { Value }\end{array}$} \\
\hline & & & M1 & M2 & M3 & \\
\hline \multirow{3}{*}{$\begin{array}{l}\text { Muscular } \\
\text { power }\end{array}$} & Measure 1 & 18.4 & & $* 1.7$ & $* \eta . r$ & \multirow{3}{*}{0.786} \\
\hline & Measure 2 & 20 & & & $* \varepsilon .7$ & \\
\hline & Measure 3 & 24.6 & & & & \\
\hline \multirow{3}{*}{$\begin{array}{l}\text { Performance } \\
\text { Endurance }\end{array}$} & Measure 1 & or.1 & & $* 1.9$ & $* \varepsilon . \wedge$ & \multirow{3}{*}{0.783} \\
\hline & Measure 2 & $0 . .1$ & & & *Y. 9 & \\
\hline & Measure 3 & $\varepsilon V . \mu$ & & & & \\
\hline \multirow{3}{*}{$\begin{array}{l}\text { Heart rate } \\
\text { During Rest }\end{array}$} & Measure 1 & $\wedge 1 . \wedge$ & & $* 1.0$ & $* 0$. & \multirow{3}{*}{1.220} \\
\hline & Measure 2 & $\Lambda \cdot r^{\mu}$ & & & $*$ *Y. & \\
\hline & Measure 3 & $\vee \vee . \wedge$ & & & & \\
\hline \multirow{3}{*}{$\begin{array}{l}\text { Vital } \\
\text { capacity }\end{array}$} & Measure 1 & $r . \wedge$ & & $* . . \wedge$ & $* 1 . \wedge$ & \multirow{3}{*}{0.516} \\
\hline & Measure 2 & $r .7$ & & & $* 1$. & \\
\hline & Measure 3 & $\varepsilon .7$ & & & & \\
\hline \multirow{3}{*}{$\begin{array}{l}\text { Forehand } \\
\text { counter } \\
\text { drive }\end{array}$} & Measure 1 & V.r & & *1. $\varepsilon$ & $* r . \wedge$ & \multirow{3}{*}{0.586} \\
\hline & Measure 2 & 1.7 & & & $* Y$. $\Sigma$ & \\
\hline & Measure 3 & 11 & & & & \\
\hline \multirow{3}{*}{$\begin{array}{l}\text { Backhand } \\
\text { counter } \\
\text { drive } \\
\end{array}$} & Measure 1 & $0 . r$ & & $* 1 . r$ & *T.r & \multirow{3}{*}{0.527} \\
\hline & Measure 2 & 7.7 & & & $* r_{\text {. }}$ & \\
\hline & Measure 3 & 1. 7 & & & & \\
\hline \multirow{3}{*}{$\begin{array}{l}\text { Forehand } \\
\text { Loop }\end{array}$} & Measure 1 & 0.7 & & $* 1$. & $* 7.1$ & \multirow{3}{*}{0.788} \\
\hline & Measure 2 & 7.7 & & & $* 0.1$ & \\
\hline & Measure 3 & 11.8 & & & & \\
\hline \multirow{3}{*}{$\begin{array}{l}\text { Backhand } \\
\text { Loop }\end{array}$} & Measure 1 & r. & & *Y.r & $* \vee .1$ & \multirow{3}{*}{0.823} \\
\hline & Measure 2 & 7." & & & $* \varepsilon . \wedge$ & \\
\hline & Measure 3 & $1 \cdot . \wedge$ & & & & \\
\hline
\end{tabular}

Table (6) indicates that there are statistically significant differences at the level of significance $(0.05)$ between the averages of the difference using the LSD test. 
mean of the dimensional measurement.

\section{Discussion:}

It is evident from the results of Table (5) that there are statistically significant differences at the level of significance between the measurements of the pre, tracker and post research sample in the physical, physiological and skills variables, which are: (Muscular power, Performance Endurance , Heart rate During Rest, Vital capacity, Forehand counter drive, Backhand counter drive, Forehand Loop, Backhand Loop) of the sample in question.

To clarify the significance of the differences between these measurements, the researcher calculated the lowest meaning difference using the LSD test to determine the significance of the differences between these measurements, as Table (6) indicates that there are statistically significant differences at the level of significance $(0.05)$ between the averages of the measurements of the pre, tracer and post research sample. In the physical, physiological and skills variables in favor of the mean of the dimensional measurement.

The researcher attributes these incident differences to the construction of the training program using circuit weight training that was applied during the special preparation period and the preparation for competitions on table tennis players for the sample under study under consideration based on our standard, which gives a positive indication of improvement in The level of physical, physiological and skills variables of the sample under study.

It is evident from Table (6) that showing there is statistically significant differences between the (pre, tracer and post) measurements for the post measurement .

This result is consistent with what the results of the study of Anttonne (2007) (1), Wilmore (1994) (15), Kerbs (2000) (10), Wolstenholm et al. (2004) (14), Mustafa Cannon (2005) (13) indicate that weight training programs lead to an increase and improvement in Physical and skill level in .

Through the above ... the researcher believes that the significance of the differences occurring between the averages 
of the research sample measurements is the subject of the research sample to the proposed circular weight training program under consideration.

And which relied in its design on the scientific rules and foundations to develop and improve the level of muscle strength and the physiological and skill variables under study.

This result verifies the validity of what was stated in the hypothesis, which states that "there are statistically significant differences between the averages of the pre-, tracerand post-measurements in the level of some physical, physiological and skill variables under study in favor of the post-measurement."

\section{conclusions:}

According to the goals and nature of this study, and within the sample of the research and the methodology applied therein, as per the data collected by the researcher and the results of statistical analysis, the researcher reached the following conclusions:

1- Training with circuit weight program is effective in the improvement of some physical variables for table tennis players.
2- $\quad$ Training with circuit weight program is effective in the improvement of some physiological variables for table tennis players.

3- $\quad$ Training with circuit weight program is effective in the improvement of some, skills variables for table tennis players.

\section{Recommendations:}

The recommendation that were based on the nature of the study, the sample, the method used and the results of statistical analysis ... the researcher was able to identify recommendations that benefit work in the field of training Table tennis players as follows: 1- Legalizing the training programs loads in light of the tribal and consecutive measurements, in order to ensure the possibility of a positive impact for these programs.

2- Paying attention to stretching and flexibility exercises (before, after) performing weight training exercises.

3- Paying attention to the technical performance "performance technique" for weight training, in order to avoid the occurrence of injuries and to make full use of the exercise performance. 
4- We need to continue training with weights during the preparation period and during the competition period to ensure Performance continues to improve.

5- Directing the results of this study, the training program used, and the steps for its implementation to workers in the field of training table tennis players ... so that they can benefit from these results. 6- The necessity of conducting more research and studies on weight training on samples of different sex and age.

References:

1 -Antonello D'Andrea, Pio Caso, Raffaella Scarafile, Gemma Salerno, Giuseppe De Corato, Claudia Mita, Giovanni Di Salvo, Filomena Allocca, Diego Colonna, Mario Caprile, et al: Biventricular myocardial adaptation to different training protocols in competitive master athletes: International Journal of Cardiology, Volume 115, Issue 3, 14 February 2007.

\section{2- Bahaa El Din Ibrahim}

Salama: Physiology of sports and physical performance (blood lactate), Dar Al Fekr Al Araby, Cairo, 2000.

3- Dan Seemiller, Mark Holowchak: winning Table Tennis Skills, Drills and
Strategies, Human Kinetics, United States of America, 1997 4- Daved Hewett: How to coach Table Tennis, William Callins \& Sons Ltd, London, 2005.

5- Ellein Wadia Farag : the referencing in Table Tennis, Almaref, Alexandria, 2002.

6-. Glenn Tepper, A Lois Rosorio, Wilhelmina Pruyn: "Table Tennis in schools program "Water Wheel press, North melbouma, Victoria, Australis, 2002 .

7- Jonny Anderson, Mark senior: Table Tennis for all , Human Kinetics, United States of America , 2004.

8- Julius kasa:"Relationship of motor abilities and motor skillsin sport games' 'faculty of physical education and sport, Comenius University, Brat salvia, Slovakia, 2005.

9- Kamal Darwish, Mohamed sobhy : Circuit Training, Alfikr alarabi for publishing, cairo 1997.

10- Kerbs, B.: Effects of Same-day Strength training on shooting skills of female, (http://Secure.sportquest.com) 2000.

11- Matt Smith, William Naty: International Table Tennis, Human Kinetics, United States of America, 2006. 
12- Mohamed Hassan Alawy (1990): Science of Sports Training, Dar Al Maaref, 10 edition, Cairo.

13- Mostfa Kanoun: The effect of a training program for muscle fitness on the physical characteristics and basic skills of junior basketball, an unpublished master's thesis, College of Physical Education for Boys, Helwan University, Cairo 2005 .

14- Woolstenhulme MT, Bailey BK, Allsen PE.:
Vertical jump, anaerobic power, and shooting accuracy are not altered 6 hours after strength training in collegiate women basketball players, Department of Physical Education, Brigham Young University, Provo, Utah 84602, USA 2004.

15- Wilmore, J.H, Castill, D.L.: Physiology of sport and exercise human kinetics, Champaign, Printed in the U.S.A, 1994. 